Article

\title{
Kilburn High Road Revisited
}

\author{
Cristina Capineri \\ Department of Social, Political and Cognitive Sciences, University of Siena, 53100 Siena, Italy; \\ E-Mail: cristina.capineri@unisi.it
}

Submitted: 4 March 2016 | Accepted: 28 June 2016 | Published: 8 July 2016

\begin{abstract}
Drawing on John Agnew's (1987) theoretical framework for the analysis of place (location, locale and sense of place) and on Doreen Massey's (1991) interpretation of Kilburn High Road (London), the contribution develops an analysis of the notion of place in the case study of Kilburn High Road by comparing the semantics emerging from Doreen Massey's interpretation of Kilburn High Road in the late Nineties with those from a selection of noisy and unstructured volunteered geographic information collected from Flickr photos and Tweets harvested in 2014-2015. The comparison shows how sense of place is dynamic and changing over time and explores Kilburn High Road through the categories of location, locale and sense of place derived from the qualitative analysis of VGI content and annotations. The contribution shows how VGI can contribute to discovering the unique relationship between people and place which takes the form given by Doreen Massey to Kilburn High Road and then moves on to the many forms given by people experiencing Kilburn High Road through a photo, a Tweet or a simple narrative. Finally, the paper suggests that the analysis of VGI content can contribute to the detection of the relevant features of street life, from infrastructure to citizens' perceptions, which should be taken into account for a more human-centered approach in planning or service management.
\end{abstract}

\section{Keywords}

content analysi; Kilburn High Road; place; VGI

\section{Issue}

This article is part of the issue "Volunteered Geographic Information and the City", edited by Andrew Hudson-Smith (University College London, UK), Choon-Piew Pow (National University of Singapore, Singapore), Jin-Kyu Jung (University of Washington, USA) and Wen Lin (Newcastle University, UK).

(C) 2016 by the author; licensee Cogitatio (Lisbon, Portugal). This article is licensed under a Creative Commons Attribution 4.0 International License (CC BY).

\section{Introduction: Volunteered Geographic Information and the City}

The domain of geographic information has been recently challenged by the availability of large quantities of crowdsourced information, namely voluntereed geographic information (VGI) (Goodchild, 2007; Sui et al., 2012), which is created by individuals more or less voluntarily thanks to Web 2.0 applications that enable information co-creation (social media, photo-sharing platforms, wiki projects, etc.) but mediated by people's values, perceptions and experiences. As with any other innovation, VGI combines technology and social practice. The technology consists of the many locationbased devices used by ordinary citizens who become sensors, and of Web 2.0 technologies, while the phe- nomenon of user-generated content is part of a cultural change which very recently has led to the adoption of open access and a collaborative and sharing approach to information resources. This cultural turn has been defined as collective intelligence by the French philosopher Pierre Levy (1994) who explains that that "the collective intelligence tries to articulate in a new way the individual and the collective domains in a new space of knowledge" (Levy, 1994, p. 33). In this context contributors are engaged in knowledge production processes, which are grounded in social structures and norms, and then in its turn, physical place (Hardy, Frew, \& Goodchild, 2012).

Recently the appeal of VGI has grown steadily and created a wide scientific community involved in the harnessing of these new sources of geographical in- 
formation. The main drivers of its success relate to:

a) The features of this information (the non-expert producers, the participatory approach, the huge quantity, the real time accessibility, the finer grained resolution and the scalability);

b) The extremely diversified fields of potential applications (disaster and crisis management, environmental monitoring, planning, land use, mobility, people's behavior and so on) which are more and more employed in governance and in the management of public services;

c) The experiential and perceptional nature of the content embedded in VGI which can be distilled both to achieve a better understanding of beliefs, practices and habits and potentially challenge the dominant narratives since VGI is built on the understanding of the social world mediated by people's conversations and contributions (Capineri, in press; Capineri \& Rondinone, 2011; Elwood, 2008, 2010).

For the domain of urban studies, VGI is a rich source of information since the settings of such data are mainly urban: most crowdsourced information-particularly data coming from social media-is produced in urban areas which combine connection facilities (internet, free wifi, hotspots, etc.) and the concentrated critical mass of city users (residents, tourists, business people, commuters, students, visitors, etc.) (Roche, Nabian, Kloeckl, \& Ratti, 2012). Indeed recent literature shows many applications of VGI dealing with different topics related to urban enviroments, such as the management of disaster relief (Zook et al., 2010), the identification of tourist flows (Girardin, Calabrese, Fiore, Ratti, $\&$ Blat, 2008), the evaluation of the attractiveness of urban space (Crandall, Backstrom, Huttenlocher, \& Kleinberg, 2009; Teobaldi \& Capineri, 2014), the dynamics of urban cores (Aubrecht, Ungar, \& Freire, 2011; Jiang \& Jia, 2011; Sagl, Resch, Hawelka, \& Beinat, 2012); the definition of cities' boundaries from geocoded social media data (Jiang \& Miao, 2015); participatory urban planning (Campagna, Floris, Massa, Girsheva, \& Ivanov, 2015; Campagna, Massa, \& Floris, 2016); public transport management (Attard, Haklay, \& Capineri, in press) and even people's affective responses in different urban contexts (Huang, Gartner, \& Turdean, 2013; Resch, Summa, Sagl, Zeile, \& Exner, 2015).

Besides the applications briefly mentioned above, local knowledge deriving from VGI has notably been applied to vernacular geography which "encapsulates the spatial knowledge that we use to conceptualize and communicate about space on a day-to-day basis" (Hollenstein \& Purves, 2010 p.22). In urban studies it is particularly interesting when contexts which can be considered "vague" need to be tackled, such as "downtown" (Hollestein \& Purves, 2010) or "neighbor- hood" (see livehoods, n.d.). More recently considerable attention has been given to the integration of perceptions and emotions in planning since they may be applied to identify aspects and areas where the citizens' wellbeing is not optimal and where action is necessary (Crooks et al., 2014; Foth, Bajracharya, Brown, \& Hearn, 2009; Resch et al., 2015).

This article reflects on the exploitation of VGI sources for qualitative and place-based analysis by using a selection of georeferenced data from Twitter and Flickr concerning Kilburn High Road in London. After this introduction, which has addressed the cultural and scientific background that has nurtured the recent development of $\mathrm{VGI}$, the paper discusses the potential of VGI for place-based analysis in Section 2; then methodology, data and the case study are explained in Section 3; the following Section 4 develops the content analysis of the VGI sources selected for the case study and presents the results. Finally the concluding remarks discuss the potential benefits of using VGI content for the formulation of policies and planning improvements.

\section{VGI and Place}

The purpose of this section is to concentrate upon place rather than space in relation to the exploitation of VGI sources. Indeed the crowdsourcing revolution has offered scientists new opportunities to apply their skills for the ever-changing discovery of the relationship between society and environment by reviving the sense of place, the idea of 'localness' and the dimension of perception which had been obscured by the quantitative revolution. In particular, VGI enables us to combine the two fundamental dimensions of the human relationship with the environment, namely space and place. Space is measure dependent and more objective in nature; place has a more subjective component which derives from its perception and from experience (consumption, use, representation, etc.). The concept of place is characterized by recurrent inconstancy throughout history, culture and communication, but generally a place can be represented or referenced according to many perspectives/points of view, dependent on what is intended to be communicated (e.g. its function, its physical properties, its values, its relationship with the subject) (Cresswell, 2013). In this way the perception of place is not trivial and perception is a fundamental feature of crowdsourced information (Capineri, in press). When utilized as a form of qualitative geographical information, the fragmented individual-level pieces of content from VGI provide a powerful source of information on the experiential dimension and on sets of values for specific places with a precision which was unattainable in the past through traditional time-constrained investigations (e.g. surveys, interviews, etc.) or official data (e.g. census). 
This paper will refer to John Agnew's theoretical basis for place-based exploration of VGI since it embraces both the geographical dimension and the meaning that objects or functions have for individuals and possibly communities. The three dimensions of place (location, locale, and sense of place) can be addressed by using VGI components (as in Purves \& Derungs, 2015). In fact, VGI consists of two main components:

a) A geographical reference (i.e. geotag, coordinates, geoname) which allows spatial representation on a map and thus addresses the notion of location, the anchorage of the information. This component consists of the digital footprints that can be represented in space as the manifestation of the producers' activity on the Web: thanks to the geocoding attributes (geotags, geonames, coordinates), the geographical origin (location) of the data can be identified. The geographical reference offers a preliminary source of information which reveals both digital activity or inactivity and the citizens' appropriation of place by naming or tagging it.

b) A stock of content which enables us to transform these data into information and eventually knowledge. The content may take different forms: images, texts, symbols, maps, check-ins, etc. Content may be either neutral/locational if it simply carries positional information (i.e. an address) or qualitative if it takes the form of descriptions, comments, images, drawings, videos. Content analysis allows us to address both the dimension of locale which expresses the settings of different experiences at locations and reveals the where of social life (workplace, shopping malls, churches, vehicles) and the sense of place expressed by feelings, emotions, statements contained in the annotations. When using VGI sources it must be kept in mind that they are digital footprints, or byproducts of human/machine interactions (Graham, 2013), generally produced by a relatively young population with skills in using Web applications.

\section{Methodology, Data and Setting}

Here we aim to use VGI to analyse Kilburn High Road (KHR) not from a space perspective but from a place perspective using VGI content since it is perceptional and experimental in nature, capable of revealing the daily routines and elements that characterize place. The aim is to compare a singular view point structured source-Massey's description of Kilburn High Road in London-with multiple viewpoint unstructured and fragmented content from VGI sources to arrive at the multiple identities suggested by Massey. The comparison will show manifestations of the locale (urban functions, services, etc.) which emerge in the context of KHR at different times, their evolution and the sense of place obtained from citizen's comments in the VGI data.

A qualitative approach for the analysis of the VGI content was selected since it was considered the most suitable both to explore a relatively large amount of unstructured data and to interpret VGI content and build explanations, not spatial patterns, from data about KHR as place such that potential explorations are 'grounded' in people's everyday experiences and actions. As with any systematic empirical investigation, VGI content analysis must proceed only after adequate preparation and organization. The preparation phase consists in collecting suitable data for content analysis and selecting the records of analysis, namely texts and annotations included in the VGI data. The organization phase includes first the classification of the data into the categories of location and locale and then extracting emotions and feelings from the texts and linking them to the locale in order to explore the sense of place, making sense of the data. This phase is important since data can be reduced to concepts that describe the research phenomenon-here KHR-by creating a conceptual system.

The data selected for the analysis are the description by Doreen Massey of Kilburn High Road which is a text of approximately 850 words (Massey, 1991, pp. 24-29), and two VGI data sets including:

a) 1493 georeferenced photos published on Flickr and collected from 2014 to 2015 with the tag "Kilburn High Road" and published by 362 users (19 users contributed $48 \%$ of the sample; 1 user accounted for $10 \%)$. Only 701 records were selected since photos with identical or incomprehensible comments were removed from the analysis. The comments attached to the photos are a rich source of information because people who take a photo choose to turn their gaze into a photo and the gaze is a socially constructed action: "Gazing is a performance that orders, shapes and classifies" (Urry \& Larsen, 2011, p. 2).

b) 691 georeferenced Tweets collected from Twitter using API from 2014 to 2015 with the tag "Kilburn High Road" produced by 423 users. Only 521 Tweets were selected for the analysis since some of them contained incomprehensible comments. Tweets are the digital footprints of KHR's users, who talk about multiple topics from trivial ones to more focussed ones about Kilburn, a sort of "stream of consciousness" as in these two Tweets: "we made these memories for ourselves" or "monkey wandering lonely as a cloud". 
These two data sets are interesting but present some limitations as it regards information about the users which must be taken into account: social media data are generally created by young people, and no reliable information about gender can be obtained from the users' profile since they often use nicknames. Nevertheless the sample of Tweets may reveal several nationalities if we consider that texts are written in 27 languages in total, of which $50 \%$ in English and $23 \%$ in Arabic, followed by French, Portuguese, Spanish, Italian, Dutch, Russian and Romanian.

After collecting the data, the analysis was organised in three steps. First, content analysis was carried out by enumerating the frequency of words (either single words or 2-3 word combinations recurring more than 3 times) in Tweets and in comments included in the Flickr photos to work out what kinds of terms emerge most frequently (e.g. road, theatre, railway bridge, etc.). Secondly, the selected terms were classified according to the three dimensions of location, locale and sense of place. The location category includes place names related to the concepts of road, neighbourhood, city and country such as "Kilburn High Road", "North West London", "Camden borough", etc. which have been used to check how users define the geographical context of KHR. The locale category includes three different groups of terms, identified by consulting the Urbamet Thesaurus: urban functions (such as transport, recreational facilities, shopping facilities, public ser- vices, built environment), street furniture (such as postbox, phone box, platform, traffic light, mural, graffiti, bridge, etc.) and activities (such as work, food, sport, events). Finally the sense of place category includes records which refer to emotions, feelings extracted from the Tweets and the photos' descriptions and associated to the selected groups of terms (e.g. unhappy $\rightarrow$ transport; useless $\rightarrow$ phone box). Linking emotions, perceptions and feelings to the locale allows us to put into context the groups of terms identified. For example, the word bus, which is one of the most frequently recurring words in the urban functions group, has been associated to records which express feelings of people travelling on them, such as this Tweet: "Have been on the bus for 30 mins. Still not out of Kilburn". This step is important because limiting the analysis to frequencies carries the risk of neglecting the wider social context that gives rise to convergences (Dittmer, 2010; Hay, 2000); moreover, the extraction of emotions highlights citizens' perspectives, preferences and needs which can be used by planners to adopt a more integrated, timely and human-centered approach (Resch et al., 2015). Indeed the sense of place includes sense of belonging, which is a prerequisite for social solidarity and collective action (Figure 1).

The setting of the analysis is an "ordinary" road, namely Kilburn High Road, located in the north west of London, more precisely in the borough of Camden.

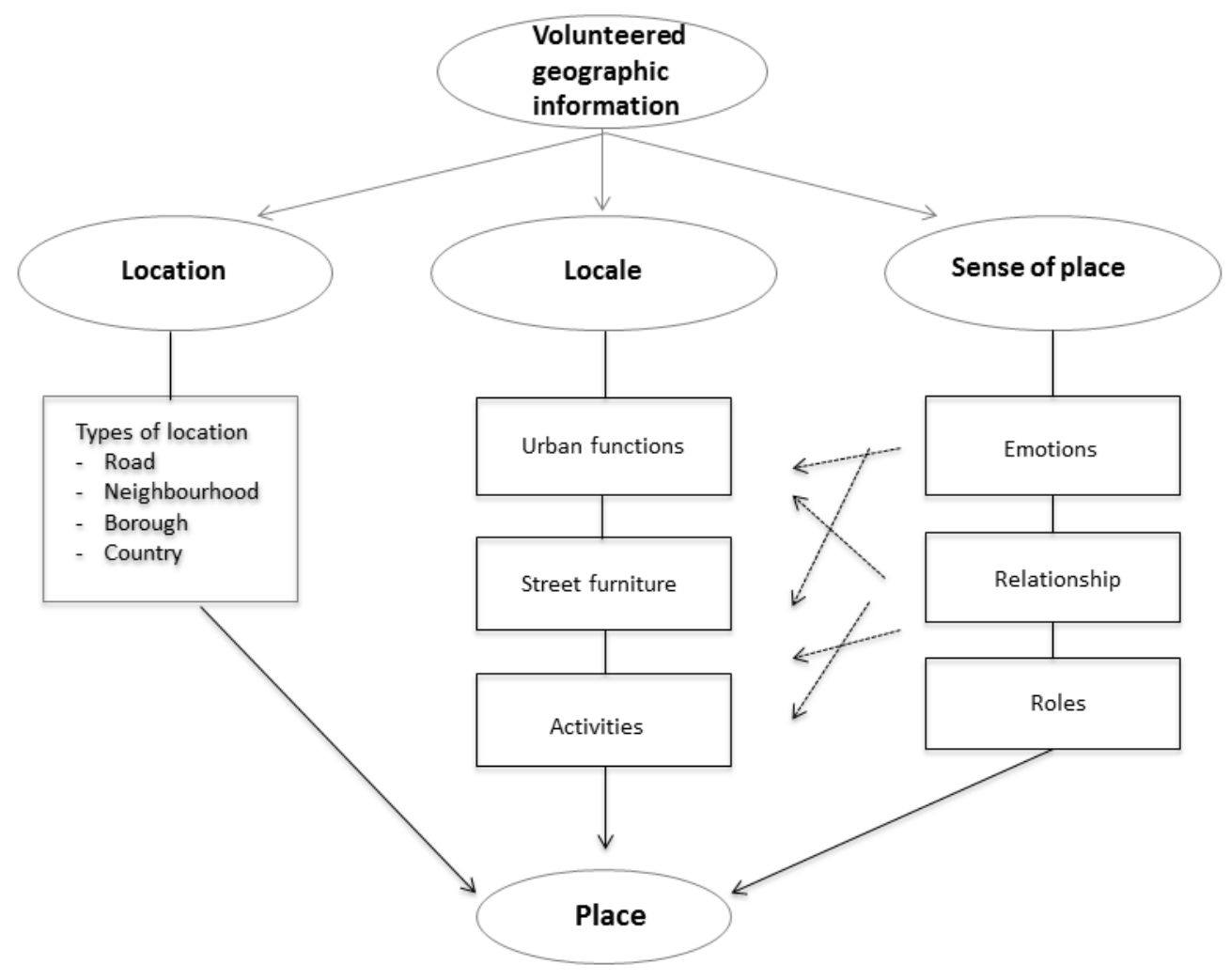

Figure 1. VGI and place: A conceptual schematic representation. 
The choice of a road as analytical setting is explained by the fact it is a conventional element of urban morphology, which is a particularly suitable laboratory for place analysis since roads are theatres of public life where objects and people are moving at different speeds and for different purposes. Elements like buildings, bus stops, gardens, lights, cars, signs, shops, houses, dogs, pubs, residents, workers, students and so on, endow the road with its distinctive essence and vitality whose analysis enables us to grasp the social life and the changing forms of the road itself (Fyfe, 2006). Here the road will not be considered as a piece of urban infrastructure but as theatre to explore the notion of place.

When Doreen Massey in her Global Sense of Place (Massey, 1991) described Kilburn High Road in London and its variegated features (the bridge, the newspaper kiosk, the Indian shop, etc.), she explained that a place has "multiple identities" which can either be "a source of richness or a source of conflict, or both". Massey argues that place should not be seen as a closed, coherent entity but as an open, complex and interconnected entity through links associated with travel, migration, culture, leisure, as well as personal biographies and memories. Doreen Massey's definition of place makes explicit some of the implications of Agnew's (1987) work: for Massey places are "networks of social relations" (Massey, 1994, p.120), that are dynamic over time; a place is a product of its linkages with other places and not just a matter of its internal features and it has a temporal dynamic. Jane Jacob too described in sharp detail the rhythms of daily life in Hudson Street in Greenwich Village, arguing that streets play a central role in establishing urban communal life (Jacobs, 1995, p.93); to achieve this it is important for the street to be 'multifunctional', not the exclusive realm of traffic or trade.

\section{The Results: From a Singular View to Multiple Identities}

Once the three steps of the analysis described in the section above have been performed, the emerging fea- tures of KHR were identified and explored also by comparing Massey's description of the 90s of the last century with the present time VGI data (Tweets and Flickr photos). Table 1 shows the distribution of the records (Tweets and Flickr descriptions) in the groups identified and the codes used to classify the records.

\subsection{Location: The Geographical Reach of KHR}

The notion of location refers to a site in space where an activity or an object is in relationship with other sites. In the text by Doreen Massey, Kilburn High Road is simply placed in "the north west of the centre London" but the VGI data offer a wider locational framework.

First of all, the distribution of the georeferenced VGI data has been mapped to represent the setting of the analysis which highlights the even distribution of VGI data along the road's course (Figure 2).

As it regards the location, the data used in the analysis reveal several other terms which place KHR in relationship to the neighbourhood and to the London area: the most frequent items in the location category are the road name (KHR) and "Kilburn", followed by "London" and "North West London" and England (Table 2). This highlights that the local scale is the most relevant and then the metropolitan one which gives a sense of belonging to a larger space.

In addition, there are several street names which occur quite frequently in the texts considered and their representation shows a sort of gravitational area around Kilburn Hgh Road, as Figure 3 illustrates. People mention these streets and roads for different purposes (meetings, cinema shows, offices, etc.) but all in all they are part of the larger KHR "espace veçu".

VGI producers also mention other locations which have a global reach such as Canada, Argentina, Palestine, Brazil, Italy, Ohio, to show that for one reason or another (sport, family, friends, work, etc.) they have links with other places: this simple fact demonstrate what Massey argued about the connections that places have at different scales.

Table 1. Distribution of Tweet and Flickr photos' records in the conceptual categories.

\begin{tabular}{|c|c|c|c|c|c|}
\hline Dimension & Category/Groups & Category/ Code & Term samples & Records & $\%$ \\
\hline LOCATION & Location & Site & Kilburn, London, Camden & 510 & 41 \\
\hline LOCALE & Urban function & Shopping facilities & shop, department store, store, Tesco, Evans & 51 & 4 \\
\hline LOCALE & Urban function & Recreational services & restaurant, cinema, theatre, McDonalds, park & 143 & 11 \\
\hline LOCALE & Urban function & Built environment & flat, terraced, cobbled, murals & 55 & 4 \\
\hline LOCALE & Urban function & Cultural heritage & Gaumont Theatre, Tricycle & 89 & 7 \\
\hline LOCALE & Activities & Events & party, match & 62 & 5 \\
\hline LOCALE & Urban function & Transport facilities & bus, railway, metro & 245 & 20 \\
\hline LOCALE & Activities & Food & club sandwich, curry, sausage & 19 & 2 \\
\hline LOCALE & Street furniture & Infrastrucures & phone box, postbox, platform, lights, bench & 17 & 1 \\
\hline LOCALE & Activities & Weather & sunny, cold, windy & 61 & 5 \\
\hline
\end{tabular}


Table 2. Most recurring terms in the location category.

\begin{tabular}{lll}
\hline Location/Site & Terms & Occurrences $(\mathbf{n})$. \\
\hline Road & Kilburn High Road & 218 \\
& Kilburn & 138 \\
& High Road & 7 \\
Neighbourhood/borough & Camden & 5 \\
& Hampstead & 5 \\
City & London & 102 \\
Country & & 9 \\
\hline
\end{tabular}

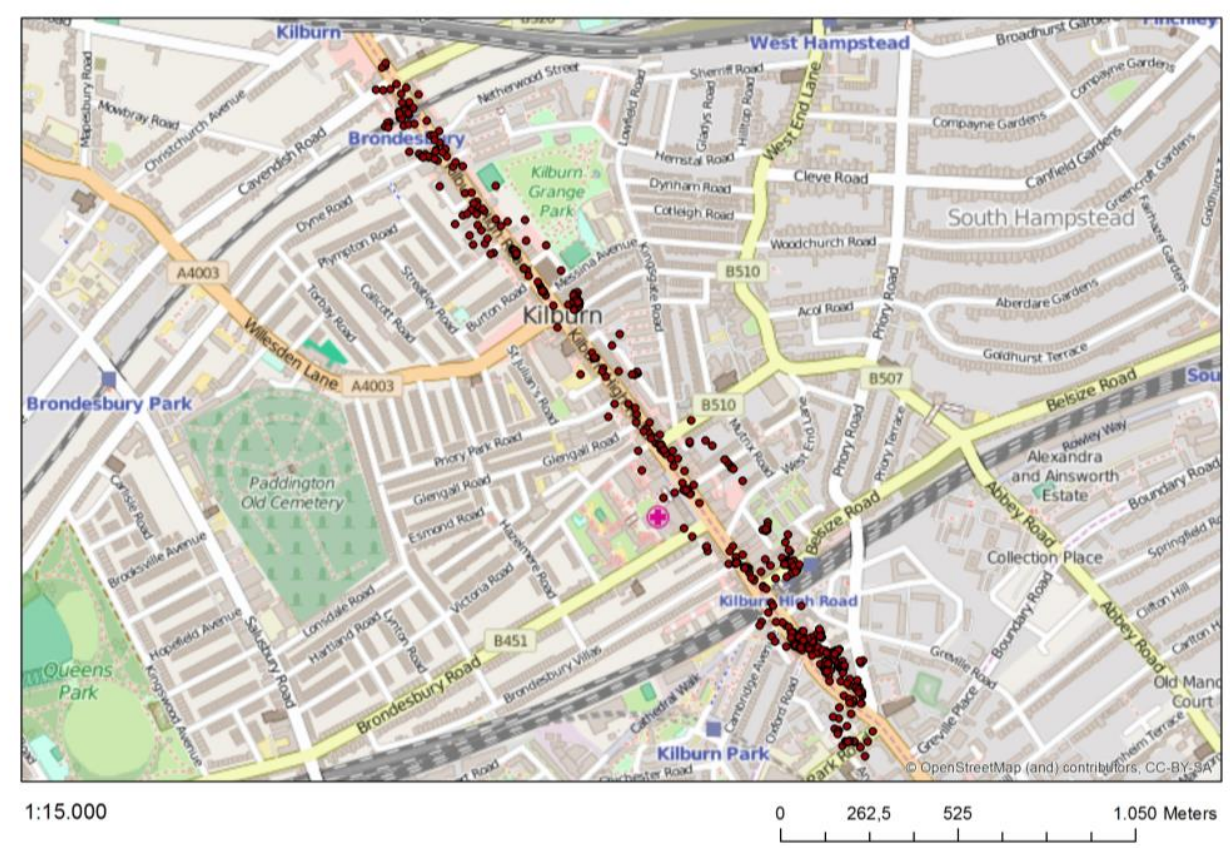

Figure 2. The distribution of georeferenced Tweets and Flickr photo along Kilburn High Road.

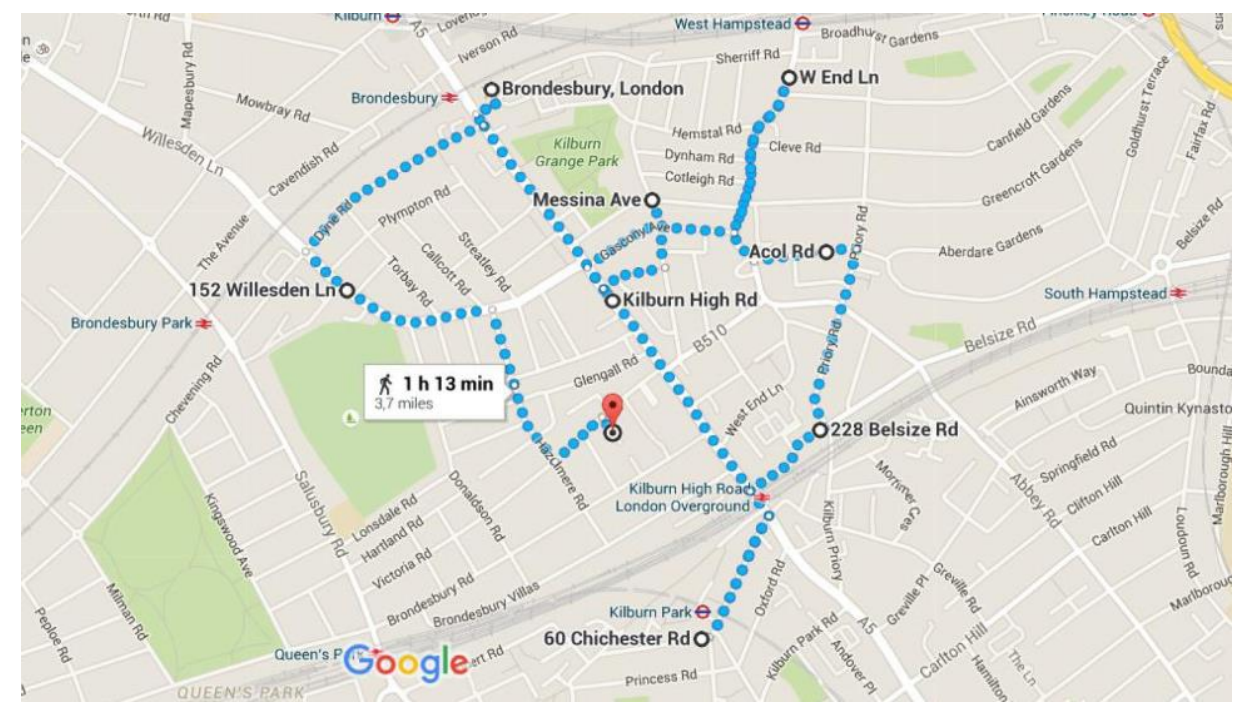

Figure 3. Emerging paths around KHR from VGI content. 


\subsection{Locale: Everyday Life in KHR}

The notion of locale, which serves to discover settings where everyday life takes place, was analysed by grouping the most frequent terms in three categories: urban functions, street furniture and activities.

\subsubsection{Urban Functions}

As regards urban functions, Massey defines Kilburn as her "local shopping centre" and her description focuses on the newspaper kiosk run by a Muslim, on the Indian clothes shop and on a few leisure facilities such as the Black Lion guesthouse, the "local theatre" (The Tricycle) and the National Club. From this "sketch", the idea of both the multiethnic and dynamic atmosphere of KHR is conveyed, together with the value of the services such as the historic guest house built in the XIX century and the theatre performances.

The other significant function relates to transport: Kilburn High Road is an important node in the London metropolitan area, as Massey comments "this is one of the main entrances to and escape routes from London, the road to Staples Corner and the beginning of the M1 to 'the North"'. The transport function seems to be a problematic feature of KHR since the traffic is defined as "stationary" and "snarled up".

When the two VGI data sets are considered, the urban functions that emerge are more diversified, as the following table shows. The selection of the most reccurrent terms (single word or up to 3 word-strings with $>3$ occurrences) converge on: recreational facilities (like theatres, cinemas, live music) and on transport facilities (see Table 3).

It is also interesting that famous global chains such as McDonalds, Starbucks and Tesco appear in the list as an effect of the globalization process in food retail which will also appear in the activities category later in this paragraph. The other "shops" seem quite ordinary ones as the many photos from Flickr show through landscape snapshots of the shopfronts along KHR (see, for example, Figure 4).

The two most cited recreational facilities are the Gaumont Cinema and the Tricycle theatre which can be considered as part of the local cultural heritage for their architectural and artistic value: the first is an art deco building and second is an innovative theatre. The fact that "conversation" converges on these items shows that they are part of Kilburn High Road's cultural identity (Figure 5 ).

On the other hand all the terms concerning transport are due to the fact that city mobility is an important and often problematic part of daily urban life. Kilburn High Road is served by several railway lines, linking the area with the city centre and the north-west suburbs. Most Flickr photos show the traditional red buses or double deckers and the iron railway bridge built in 1852 as icons of local transport (Figure 6).

Table 3. Most frequently recurring terms in the urban functions category.

\begin{tabular}{|c|c|c|c|c|c|}
\hline \multicolumn{6}{|c|}{ Locale/Urban functions } \\
\hline $\begin{array}{l}\text { Recreational } \\
\text { services }\end{array}$ & $\begin{array}{l}\text { Occurrence } \\
\text { (n.) }\end{array}$ & $\begin{array}{l}\text { Transport } \\
\text { facilities }\end{array}$ & $\begin{array}{l}\text { Occurrence } \\
\text { (n.) }\end{array}$ & $\begin{array}{l}\text { Shopping } \\
\text { facilities }\end{array}$ & $\begin{array}{l}\text { Occurrence } \\
\text { (n.) }\end{array}$ \\
\hline The Black Lion & 39 & bus & 34 & shops & 33 \\
\hline Gaumont Cinema & 38 & stations & 19 & store & 9 \\
\hline Tricycle Theatre & 38 & train & 12 & laundrette & 3 \\
\hline Kilburn Park & 22 & $\begin{array}{l}\text { Kilburn High Road railway } \\
\text { station }\end{array}$ & 8 & Tesco food & 3 \\
\hline theatre & 19 & car park & 6 & & \\
\hline cinema & 18 & Bakerloo Line & 6 & & \\
\hline Cock Tavern Theatre & 18 & Metropolitan Railway & 6 & & \\
\hline pub & 15 & Kilburn High Road Station & 4 & & \\
\hline Luminaire music hall & 13 & North London Line & 3 & & \\
\hline Queens Park & 8 & Kilburn High Road tube station & 3 & & \\
\hline restaurant & 6 & & & & \\
\hline hotel & 6 & & & & \\
\hline McDonalds & 5 & & & & \\
\hline Sichuan restaurant & 5 & & & & \\
\hline Grange Cinema & 4 & & & & \\
\hline \multicolumn{6}{|l|}{ North London } \\
\hline Tavern & 4 & & & & \\
\hline cafe & 3 & & & & \\
\hline club & 3 & & & & \\
\hline Red Lion & 3 & & & & \\
\hline Starbucks & 3 & & & & \\
\hline
\end{tabular}




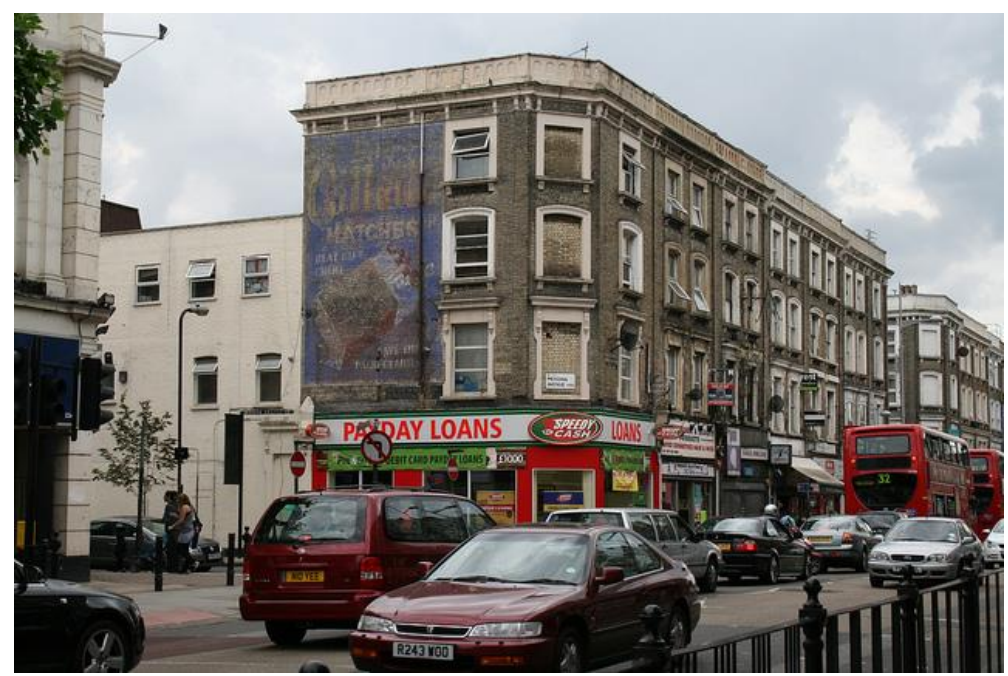

Figure 4. A panorama of KHR shopfronts. Source: Flickr, The Creative Commons.

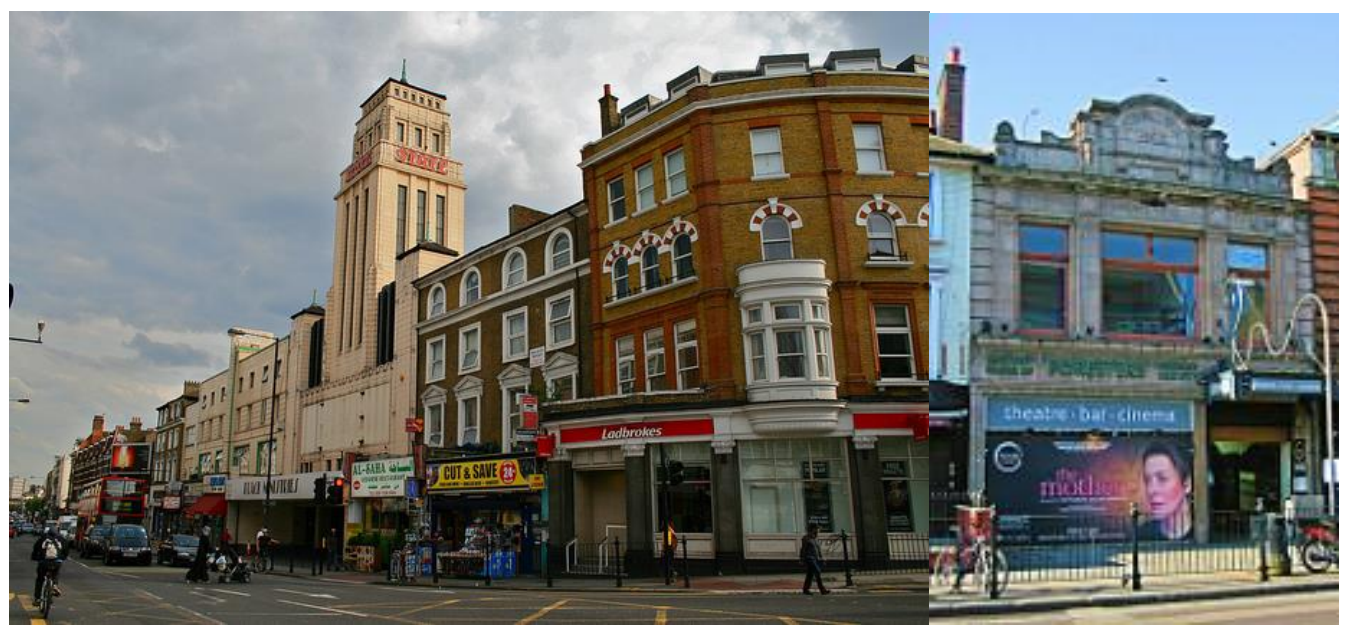

Figure 5. The Gaumont Cinema (right) and the Tricycle theatre (left) in KHR. Source: Flickr, The Creative Commons.

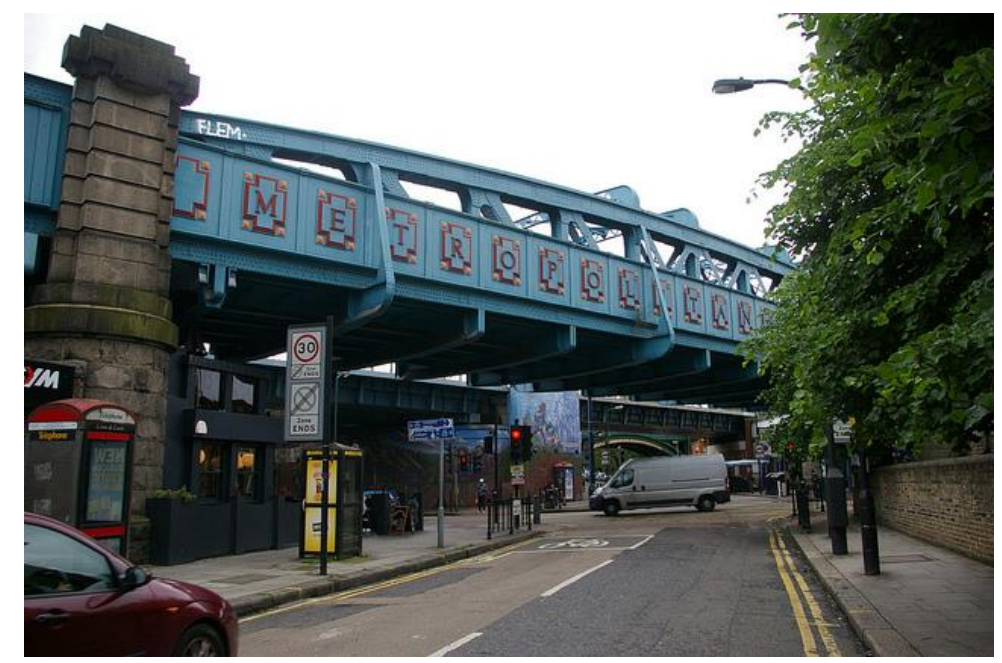

Figure 6. Kilburn High Road railway bridge. Source: Flickr, The Creative Commons.

\subsubsection{Street Furniture}

Moving on to the street furniture category, another aspect of street life is taken into consideration. All the items (e.g. postboxes, phone boxes, traffic lights, traffic signs, bus stops, etc.) are utilitarian in nature but also have a symbolic value which builds the identity of the street and relates more generally to the national culture: an example could be the British red phone box. As Jane Jacobs pointed out: "a sidewalk life arises only 
when the concrete, tangible facilities it requires are present....If they are absent, public sidewalk contacts are absent too" (Jacobs, 1961 p. 93).

In Massey's sketch, street furniture consists of posters on the wall relating to political and social conflicts (such as references to the Irish Free State, letters from the IRA), notices recording lottery winners or announcing forthcoming concerts, with many postboxes along the road. The flow of VGI, in contrast, offers a strong convergence on street murals and graffiti, a recent expression of street art, and on items linked with transport (e.g. the platform, the junction), street lights and the traditional phone boxes (Table 4).

In particular the phone box, which seems to be a relic of the past but is without doubt a traditional item in the British urban landscape, produces some nostalgic feelings as will be demonstrated later. These terms emerge particularly from the georeferenced photos on Flickr.

\subsubsection{Activities}

The terms selected in the activities group refer to actions or behaviours of different kinds which are performed by VGI producers. This category includes terms related to everyday activities, from work to transport and food, sports and free time (Table 5).

The activities which emerge from the VGI data refer to very common habits like eating out with friends, going to parties and concerts, or doing paperwork. In particular, terms concerning food highlight, as with the shops, typical globalized items like burgers, sandwiches or the appreciation for ethnic food like kebabs or Indian and Chinese dishes (e.g. pitta bread, noodles); moreover people's comments also converge on some comfort foods, like the chocolate-coated bananas or the vanilla icecream. It is interesting that the drinks mentioned include beer and coffee but omit the more traditional English tea.

\section{Sense of Place}

The last category to be addressed is sense of place. Massey describes KHR from an affective point of view, "Kilburn is a place for which I have a great affection; I have lived there many years" which embodies the features of place by presenting it as a community with its inhabitants and their relationships with the street environment.

Table 4. Most frequently recurring terms in street furniture category.

\begin{tabular}{ll}
\hline Locale/Street furniture & Occurences $(\mathbf{n})$. \\
\hline murals and graffiti & 52 \\
junction & 25 \\
side platform & 14 \\
sign & 11 \\
stairs & 8 \\
lights & 7 \\
phone boxes & 4 \\
building dates & 5 \\
island platform & 5 \\
station name & 5 \\
gardens & 4 \\
bench & 3 \\
neon lights & 3 \\
traffic light & 2 \\
street art & 2 \\
\hline
\end{tabular}

Table 5. Most recurring terms in the "activities" category.

\begin{tabular}{|c|c|c|c|c|c|c|c|}
\hline \multicolumn{8}{|c|}{ Locale/Activities } \\
\hline Food & $\begin{array}{l}\text { Occurences } \\
\text { (n.) }\end{array}$ & Sport & $\begin{array}{l}\text { Occurences } \\
\text { (n.) }\end{array}$ & Events & $\begin{array}{l}\text { Occurences } \\
\text { (n.) }\end{array}$ & Work & $\begin{array}{l}\text { Occurences } \\
\text { (n.) }\end{array}$ \\
\hline beer & 10 & World cup & 22 & match & 8 & work & 50 \\
\hline coffee & 9 & football & 20 & film & 7 & job & 10 \\
\hline beefburger & 5 & jogging & 6 & concert & 6 & watch & 6 \\
\hline chicken & 5 & tennis & 5 & music & 5 & write & 5 \\
\hline club sandwich & 4 & walking & 3 & home parties & 4 & dissertation & 3 \\
\hline shish kebab & 4 & yoga & 3 & parties & 3 & paperwork & 3 \\
\hline chicken pitta & 3 & Wimbledon & 2 & garden parties & 3 & workshop & 3 \\
\hline vanilla ice cream & 3 & play & 3 & & & office & 3 \\
\hline noodles & 3 & & & & & & \\
\hline lamb & 3 & & & & & & \\
\hline $\begin{array}{l}\text { chocolate coated } \\
\text { banana }\end{array}$ & 2 & & & & & & \\
\hline lolly & 2 & & & & & & \\
\hline salad & 2 & & & & & & \\
\hline rice & 2 & & & & & & \\
\hline
\end{tabular}


In order to grasp the sense the of place at KHR, records with terms or expressions revealing emotions and feelings have been manually selected and linked to each category (transport, street furniture, etc.) trying to collect at least 3 records containing terms or expressions related to emotions. The selection is rather difficult because the analysis of VGI sources shows that feelings and emotions are not always expressed by single words like happy, unhappy, love or hate but rather with expressions of more that one word that reveal the state of mind. For example the sentence "I am single again", may convey the idea of loneliness but this feeling is not clearly stated in the annotation; or does the Tweet "Club sandwich in front of me on the bus" mean the traveller is hungry or annoyed?

Furthermore, only a limited number of records contain emotional expressions which can be linked to the categories, as Table 6 shows.

The combination of categories and emotional con- tents highlight the recurring feelings on the emerging terms identified in the analysis on Kilburn High Road, as the samples in Table 7 explain.

Table 6. Records containing emotional terms and expressions extracted for each category.

\begin{tabular}{ll}
\hline Category & $\begin{array}{l}\text { Records containing } \\
\text { emotional terms \& } \\
\text { expressions }\end{array}$ \\
\hline Location /Site & 40 \\
Urban functions & \\
Recreational services & 8 \\
Built environment & 12 \\
Transport & 40 \\
Activities & 15 \\
Street furniture & 12 \\
\hline
\end{tabular}

Table 7. Samples of records selected for exploration of emotions \& feelings.

\begin{tabular}{|c|c|c|}
\hline Dimension & Category & Records with emotional \& perceptional contents (samples) \\
\hline Location & $\begin{array}{l}\text { Site } \\
\text { (KHR) }\end{array}$ & $\begin{array}{l}\text { "I really love Kilburn". } \\
\text { "Enjoying too much here I don't wanna go home". } \\
\text { "Kilburn High Road has always been a bustling and vibrant place and a couple of recent visits has } \\
\text { shown me it still is". } \\
\text { "I took this walking along Kilburn High Road after going to a football match. I liked the atmospheric } \\
\text { feel that the streetlight gave to the bricks and cobbles". } \\
\text { "A bland-looking place alongside Kilburn High Rroad station" } \\
\text { "I love the old people, even the grumpy old crows! They're amazing" } \\
\text { "The southernmost part of the road, south of the junction with Marylebone Road, is noted for its } \\
\text { distinct Arab flavour". } \\
\text { "all Hindus are cordially invited" (Massey, 1991). }\end{array}$ \\
\hline Locale & Transport & $\begin{array}{l}\text { "oh dear a truck broken down". } \\
\text { "I hate strangers sitting next to me on the bus". } \\
\text { "have been on the bus for } 30 \text { mins.Still not out of Kilburn". } \\
\text { "Erratic is the only way to describe driving in London". } \\
\text { "I don't know what's worse, driving in London or using Londons public transport. Both will } \\
\text { eventually cause me a heart attack". }\end{array}$ \\
\hline Locale & $\begin{array}{l}\text { Recreational } \\
\text { facilities }\end{array}$ & $\begin{array}{l}\text { "You can see Nandos on the left. Woody Grill on the right". "There are many pawn brokers on the } \\
\text { street as well as pay day loan shops, gambling machine shops and betting shops". }\end{array}$ \\
\hline Locale & $\begin{array}{l}\text { Street } \\
\text { furniture }\end{array}$ & $\begin{array}{l}\text { "Using phone boxes is still a thing?". } \\
\text { "I cannot imagine how long this mural has been here, advertising matches, so different in its faded } \\
\text { glory from the glossy flashy ads that have superceded it". } \\
\text { "By contrast, large murals under rail bridges near Kilburn Station. Part of the aim of the Kilburn } \\
\text { murals was celebrate the "vast multiculturalism" of that part of London. Also to involve members of } \\
\text { the local community as the murals were painted". } \\
\text { "I think there's a very clear line between street art and graffiti". } \\
\text { "dust, dog poo". } \\
\text { "pigeons should get fined...". } \\
\text { Yet, the flashy lights attract me-the neons, the fluorescents and the ever changing traffic } \\
\text { lights. This city is always lit. A bit too well lit sometimes. }\end{array}$ \\
\hline Locale & Activities & $\begin{array}{l}\text { "Club sandwich in front of me on the bus". } \\
\text { "\#fish and \#chips \#fincity \#kilburn\#london". } \\
\text { "@NandosUK \#nandos [restaurant] KILBURN". } \\
\text { "\#hotChocolate \#Starbucks \#myJob @KilburnHigh Road". } \\
\text { "Woke up to a kabanos in our bathroom. And a mini version of those smooth Turkish beef } \\
\text { sausages. Our cats are such cultured scavengers". }\end{array}$ \\
\hline
\end{tabular}


After reading these annotations, some remarks may be made on the emerging sense of place of KHR: a busy and vibrant road characterized by heavy and congested traffic, with a multiethnic population which seems to be comfortable in the neighbourhood despite the typical drawbacks of the urban environenment such traffic congestion, litter or light pollution. The comparison with Massey's description also reveal some changes, particularly in the shopping facilities (the local shops replaced by department stores) and in street furniture (the posters replaced by murals) but also the permanence of problematic features (the congested traffic) and of cultural heritage (such as the Gaumont Cinema, the Tricycle theatre). The explorations of the sense of place derived from VGI annotations could be developed further, but the aim here has been to concentrate on the most relevant aspects of the road while giving examples of the potentialities of VGI in dealing with urban matters. The lessons learnt from the analysis could certainly be used to improve the quality of life and to finetune planning initiatives in those fields which emerge from citizens' footprints: the case study identified, for example, traffic, light pollution, litter as relevant features on which conversation converges. As argued by recent literature (Campagna et al., 2015; Crooks et al., 2014; Foth et al., 2009), VGI can complement existing authoritative geographic information in giving planners near real-time information not only about rapid changes in the physical environment but also about social processes in space and time. In addition, such sources offer unprecedented potential in the investigation of community perspectives, preferences and needs (Resch et al., 2015).

\section{Conclusions}

The paper has shown some of the potential of volunteered geographic information when an urban context has been analyzed from a qualitative point of view.

The singular point of view of KHR by Doreen Massey has been supplemented by the palimpsest of information derived from VGI sources which has brought together the informal knowledge of the content and become a collector of multiple points of view. This multiplicity of identities has highlighted the many emotional relationships within KHR such as appreciation, criticism, sharing and reacting and so on.

In addition, the identification of emerging terms has revealed the "sticky features" in the fluid space of digital information: the categories identified are clusters of information which not only tell stories of location (the where) but collects the added value generated by the producers' annotations that build the sense of place.

In this context VGI enables a better understanding of place identity and dynamics since place is a process that is continually reproduced through a distinct mix of wider and social relations.
The exploitation of VGI has so far been characterized by a preoccupation with representing crowdsourced information on maps that often all look the same, since patterns are strongly biased by the heavily concentrated production areas of crowdsourced information. Maybe narratives should go beyond the map to address territoriality and place (Roche, 2015) and exploit the inner meaning of the crowdsourced content, highlighting conflicts, convergences, power relationships, values and practices, as we have tried to do in this paper.

In conclusion, the VGI sources produced more or less voluntarily by non-expert people have shown two important qualities that could also be employed in urban planning: a) content created or edited by individuals will eventually converge on a consensus on features, preferences, values; b) they may tell 'stories' about places, unknown to the wider public, and consolidate knowledge, mainly at local level, which could remain unseen because it is remote from the places where decisions are made. As Jane Jacobs wrote: “Designing a dream city is easy; rebuilding a living one takes imagination" (Jacobs, 1958).

\section{Acknowledgments}

The author would like to thank John Agnew (University of California, Los Angeles), Gilles Falquet (University of Geneva), and Rob Lemmens (University of Twente) who provided insight and expertise that greatly assisted the research, although they may not agree with all of the interpretations/conclusions of this paper. The other acknowledge the support of COST Action IC1203 European Network Exploring Research into Geospatial Information Crowdsourcing: software and methodologies for harnessing geographic information from the crowd (ENERGIC).

\section{Conflict of Interests}

The author declares no conflict of interests.

\section{References}

Agnew, J. A. (2014). Place and politics: The geographical mediation of state and society (Vol. 1). New York: Routledge.

Attard, M., Haklay, M., Capineri, C. (in press). The potential of volunteered geographic information (VGI) in future transport systems. Urban Planning, 1(4).

Aubrecht, C., Ungar, J., \& Freire, S. (2011). Exploring the potential of volunteered geographic information for modeling spatio-temporal characteristics of urban population. In Proceedings of 7VCT (pp. 18-13). Lisbon: 7VCT.

Campagna, M., Floris, R., Massa, P., Girsheva, A., \& Ivanov, K. (2015). The role of social media geographic information (SMGI) in spatial planning. In Planning 
Support Systems and Smart Cities (pp. 41-60). Chalm: Springer International Publishing.

Campagna, M., Massa, P., \& Floris, R. (2016) The role of social media geographic information (SMGI) in geodesign. Journal of Digital Landscape Architecture. doi:10.14627/537612019

Capineri, C. (in press). The nature of volunteered geogaphic information. In C. Capineri, M. Haklay, H. Huang, R. Purves, V. Antoniou, \& J. Kettunen (Eds), European handbook of crowdsourced information. London: Ubiquity Press.

Capineri, C., \& Rondinone, A. (2011). Geografie (in) volontarie. Rivista geografica italiana, 118(3), 555573.

Crandall, D. J., Backstrom, L., Huttenlocher, D., \& Kleinberg, J. (2009). Mapping the world's photos. In Proceedings of the 18th international conference on World wide web (pp. 761-770). Madrid, Spain: ACM.

Cresswell, T. (2013). Place: A short introduction. London: John Wiley \& Sons.

Creswell, J. W. (2013). Qualitative inquiry and research design: Choosing among five approaches. Thousand Oaks, CA: Sage.

Crooks, A., Pfoser, D., Jenkins, A., Croitoru, A., Stefanidis, A., Smith, D., . . . Lamprianidis, G. (2014). Crowdsourcing urban form and function. International Journal of Geographical Information Science, 29(5), 1-22.

Dittmer, J., (2010). Textual and discourse analysis. In D. Delyser, S. Herbert, S. Aitken, M. Crang, \& L. McDowell (Eds.), The SAGE handbook of qualitative geography (pp. 274-286). Thousand Oaks, CA: Sage

Elwood, S. (2008). Volunteered geographic information: Key questions, concepts and methods to guide emerging research and practice. GeoJournal, 72(3), 133-135.

Elwood, S. (2010). Geographic information science: Emerging research on the societal implications of the geospatial web. Progress in Human Geography, 34(3), 349-357.

Foth, M., Bajracharya, B., Brown, R., \& Hearn, G. (2009). The second life of urban planning? Using neogeography tools for community engagement. Journal of Location Based Services, 3(2), 97-117.

Fyfe, N. (2006). Images of the street: Planning, identity and control in public space. London: Routledge.

Girardin, F., Calabrese, F., Fiore, F. D., Ratti, C., \& Blat, J. (2008). Digital footprinting: Uncovering tourists with user-generated content. Pervasive Computing, IEEE, 7(4), 36-43.

Goodchild, M. F. (2007). Citizens as sensors: The world of volunteered geography. GeoJournal, 69(4), 211-221.

Graham, M. (2013). The virtual dimension. In M. Acuto \& W. Steele (Eds.), Global city challenges: Debating a concept, improving the practice. London: Palgrave.

Hay, I. (2000). Qualitative research methods in human geography. Oxford, UK: OUP.
Hardy, D., Frew, J., \& Goodchild, M. F. (2012). Volunteered geographic information production as a spatial process. International Journal of Geographical Information Science, 26(7), 1191-1212.

Hollenstein, L., \& Purves, R. (2010). Exploring place through user-generated content: Using Flickr tags to describe city cores. Journal of Spatial Information Science, 2010(1), 21-48.

Huang, H., Gartner, G., \& Turdean, T. (2013). Social media data as a source for studying people's perception and knowledge of environments. Mitteilungen der Österreichischen Geographischen Gesellschaft, 155, 291-302.

Jacobs, J. M. (1958). Downtown is for people. The exploding metropolis, 168.

Jacobs J. M. (1961). The death and life of great American cities. New York: The Modern Library.

Jiang. B., \& Jia, T. (2011). Zipf's law for all the natural cities in the United States: A geospatial perspective. International Journal of Geographical Information Science, 25(8), 1269-1281.

Jiang, B., \& Miao, Y. (2015). The evolution of natural cities from the perspective of location-based social media. The Professional Geographer, 67(2), 295-306.

Levy, P. (1994). L'Intelligence collective. Pour une anthropologie du cyberespace. Paris: La Découverte.

livehoods. (n.d.). Homepage. livehoods. Retrieved from http://livehoods.org

Massey, D. (1991). A global sense of place. Marxism Today, 38, 24-30.

Massey, D. (1994). Place, space and gender. Minneapolis, MN: University of Minnesota.

Purves, R. S., \& Derungs, C. (2015). From space to place: Place-based explorations of texts. International Journal of Humanities and Arts Computing, 9(1), 74-94.

Resch, B., Summa, A., Sagl, G., Zeile, P., \& Exner, J. P. (2015). Urban emotions-Geo-semantic emotion extraction from technical sensors, human sensors and crowdsourced data. In Progress in Location-Based Services 2014 (pp. 199-212). Chalm: Springer International Publishing

Roche, S., Nabian, N., Kloeckl, K., \& Ratti, C. (2012). Are 'smart cities' smart enough? Global geospatial conference 2012. Québec, Canada: Global Spatial Data Infrastructure Association. Retrieved from http:// www.gsdi.org/gsdiconf/gsdi13/papers/182.pdf

Roche, S. (2015). Geographic information science II. Less space, more places in smart cities. Progress in Human Geography. doi:10.1177/0309132515586296

Sagl, G., Resch, B., Hawelka, B., \& Beinat, E. (2012). From social sensor data to collective human behaviour patterns: Analysing and visualising spatio-temporal dynamics in urban environments. In Proceedings of the GI-Forum 2012: Geovisualization, society and learning (pp. 54-63). Salzburg, Austria: University of Salzburg.

Sui, D., Elwood, S., \& Goodchild, M. (2012). Crowdsourc- 
ing geographic knowledge: Volunteered geographic information (VGI) in theory and practice. Chalm: Springer International Publishing

Teobaldi, M., \& Capineri, C. (2014). Experiential tourism and city attractiveness in Tuscany. Rivista Geografica Italiana, 121(3), 259-274.
Urry, J., \& Larsen, J. (2011). The tourist gaze 3.0. London: Sage.

Zook, M., Graham, M., Shelton, T., \& Gorman, S. (2010). Volunteered geographic information and crowdsourcing disaster relief: A case study of the Haitian earthquake. World Medical \& Health Policy, 2(2), 7-33.

\section{About the Author}

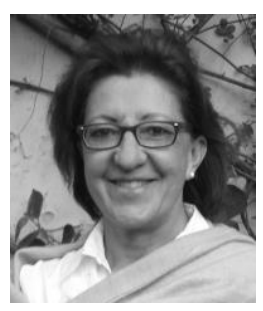

Cristina Capineri is associate professor of geography at the Department of Social, Political and Cognitive Studies (DISPOC), University of Siena, Italy. Her research interests concern broadly transport and telecommunication networks, Giscience and volunteered geographic information, local development and sustainable development, environmental indicators, organic agriculture and landscape. 